\title{
Effects of Topical Honey Dressing on Infected Wounds after Gynecological and Obstetrical Abdominal Surgery
}

\section{Mona Abd El-Haleem Ebraheem El-Agamy}

Assistant lecturer Maternity and Gynecological Nursing

Faculty of Nursing, Tanta University.

\section{Prof. Dr.Shadia Abd El-kader Hassan}

Maternity and Newborn health Nursing,

Faculty of Nursing, Cairo University.

\section{Naeim Fatoh El Far}

Prof. of Microbiology,

Faculty of Medicine, Tanta University.

\section{Iman Abd El-Azziz El-Khayat}

Lecturer of Maternity and Gynecological Nursing,

Faculty of Nursing, Tanta University.

\begin{abstract}
Despite use of prophylactic antibiotics, wound infections remain common. Post operative wound infections develop in $4 \%$ of patients following inpatient gynecologic surgery and in $5 \%$ to $7 \%$ of patients undergoing primary cesarean section. The use of honey as a wound dressing material is an ancient remedy that has been rediscovered.

The aim of the study is to evaluate the effects of topical honey dressing on infected wounds after obstetrical and gynecological abdominal surgery as compared to the routine hospital wound care. This study was conducted on 60 women were recruited from Tanta University hospitals at Obstetrical and Gynecological Department. Where 30 of them were dressed according routine wound care of the hospitals, which includes local antiseptics, daily dressing, and antibiotic. And the others were dressed by honey (Api-care) dressing plus the routine hospital wound care.
\end{abstract}

Vol. 3 No. 2 November 2012 


\section{Tanta Scientific Nursing Journal}

The result of the study revealed that the mean age of the honey group was $30.87 \pm 8.41$ while the other groups mean age was $35.17 \pm 9.92$ which was statistically not significant $(\mathrm{p}=0.061)$. Results of honey dressing showed remarkable change compared to other method. After 6 days of dressing, wound appearance among those dressed by honey was normal among $100 \%$ of cases compared to grey or white pallor appearance for the other group. Honey dressed group showed $100 \%$ significant improvement, mild pain, non exudates which was significantly different from other group ( $\mathrm{p}=0.001)$. the mean duration of management of cases with honey was found to be 11 days compared to 20 cases for other group which was found to be significantly different at $\mathrm{p}=0.001$. The researcher concluded that topical application of sterile topical honey cream (Apicare) could eradicate organisms within short time, reduce period of antibiotic use, accelerate the healing process in unique and economic way, result in minimal scar formation, prevent wound dehiscence and need for re- suturing. weight, $15.8 \%$ in overweight, and 37.5 in obese women.

Vol. 3 No. 2 November 2012 


\section{$\underline{\text { Introduction }}$}

Hysterectomy and cesarean section are the most commonly performed operations among inpatients at Egyptian Hospital ${ }^{(1)}$. The two most frequent complications of these surgeries are fever and surgical site infections (SSIs). The use of prophylactic antibiotics in hysterectomy and cesarean section in Egyptian hospitals is not standardized and is determined by the consultant in charge of the case. Inappropriate and prolonged use of antibiotics is a serious problem. It increases the morbidity and mortality of patients and also increases health care costs due to increased antibiotic resistance rates ${ }^{(2)}$.

SSIs developed in $4 \%$ of inpatient undergone gynecologic surgery and in 5\% to $7 \%$ of patients' undergone primary cesarean section ${ }^{(1,3)}$. According study In Egypt about wound infection after Cesarean Section and women weight; wound infections were $11.4 \%$ in normal Surgical site infections (SSIs) continue to pose a major problem for many surgery patients. Its occurrence is associated with readmission, repeated surgery or intervention, prolonged hospitalization and significant clinical and economic consequences ${ }^{(4)}$. The risk is particularly high in developing countries due to mal-nutrition, illiteracy, improper surgical technique, substandard sterilization of operation theatres and inadequate or over burdened health facilities ${ }^{(5,6,7)}$. Data on SSI rates is not available in Egypt; however, other sources of data suggest that there is poor compliance in aseptic techniques and Increase the cost of the hospital stay $7-8$ days for a SSI ${ }^{(7)}$. In Egypt, every one Egyptian pound spent for infection control saves 60 Egyptian pound spent on nosocomial infection ${ }^{(8)}$.

Nursing care of the female surgical patient requires an accurate understanding of the pathophysiologic changes that occur perioperatively. The nurse should maintain proper environment and appropriate interventions; the first nurse's goal during the postoperative period is to provide appropriate support that allows for the maintenance of homeostasis and the prevention of potential complications. The second goal is to recognize unfavorable 
trends in the course of recovery and respond expeditiously to prevent further compromise. Much information can be obtained by close monitoring of vital signs. Changes of these measurements reflect the patient's ongoing condition ${ }^{(9)}$.

The management of the incision is based on the normal biology of the healing process, which is conceptually divided into three phases. Initial phase (inflammation), second phase (fibroblast proliferation) and, third phase (maturation). The operative dressing can be removed after 24-48 hours. If wound drainage is noted upon inspection, a sterile dressing must be replaced until the drainage ceases and closure is attained. On the other hand, allowing sutures to stay in place for a long period increases scar formation at the sites of skin penetration. In healthy individuals with an abdominal incision, sutures can be removed on the third postoperative day. ${ }^{(9.10)}$. Temperature elevation higher than $\left(38^{\circ} \mathrm{C}\right)$ in the surgical patient should alert the nurse of potential complications. Evaluation and subsequent therapy are dependent on how soon after surgery the fever develops. Postoperative fever in the First 24-48 hours may refer to wound infection. Signs may include crepitus, pain, and edematous discoloration. Treatment consists of aggressive intraoperative debridement and drainage and broad-spectrum antibiotics. The use of drains, tubes, and suction devices at the wound site is often necessary to promote healing. It is important to know the type of drain or tube in use so that patency and placement can be accurately assessed. Once a diagnosis of wound infection has been confirmed and antibiotic sensitivities identified, appropriate management regimens should be considered, with a high priority given to reducing the risk of cross infection. It is important to treat the patient as a whole and not the infection alone, so management strategies must be based on data driven from a holistic assessment of individual needs ${ }^{(11,12,13)}$.

Many researchers supported the use of honey in managing infected wounds and stated its prophylactic use on the wounds of patients susceptible to infections and antibiotic-resistant bacteria. Egyptian honey is effective as an antibacterial agent against 
different pathogenic bacteria. Most of honey samples can completely inhibit the growth of all bacteria. The use of honey as a wound dressing material is an ancient remedy that has been rediscovered. Honey is produced from many different floral sources and its antibacterial activity varies with origin and processing. Honey selected for clinical use should be evaluated on the basis of antibacterial activity levels determined by laboratory testing. Antibacterial properties of honey include the release of low levels of hydrogen peroxide and phytochemical antibacterial components. So appropriate use of topical honey dressing helps to reduce the bacterial burden on the wound surface $(4,10,14)$

Post operative obstetrical and gynecological nursing professionals play a crucial role in early detection of wound infections. Failure to do this, can result in serious patients' outcomes. Post operative nurses can expand their current efforts through implementing strategies to providing effective management of infected surgical wound $(11,12,13,15)$. Practical guide on the use of honey in managing infected surgical wounds, such as amount of honey, concentration, type of dressing, appropriate use and frequency were considered and followed by the researcher. So, this research was carried out to early detection of SSIs and examines the effects of honey dressing on optimal healing of infected abdominal surgical wound of obstetrical \& Gynecological surgeries.

\section{The aim of the study was:-}

To evaluate the effects of topical honey dressing on infected wounds after obstetrical and gynecological abdominal surgery as compared to the routine hospital wound care.

\section{Materials and Method}

\section{Subjects:}

A total sample of 60 women was recruited from the previously mentioned setting, through the first three days after the surgery according the following criteria:

Women are in the childbearing age (16-49 year). Post operative abdominal obstetrical or gynecological patients. Appearance of surgical site infection signs or symptoms such as; redness, tenderness, infected discharge, bad smell in the wound, fever more than $38^{\circ} \mathrm{C}$, faster pulse rate and faster breathing. Signs and symptoms of infection 
would are confirmed by wound culture.

Excluding patients who have any medical disorder as; cardiac failure, chronic respiratory problems, vascular disorders, diabetes, renal and liver insufficiency and, patients with hemoglobin $\leq 8 \mathrm{mg} / \mathrm{ml}$. In addition, patient receiving drug therapies which may interfere with wound healing as chronic steroid therapy, immunosuppressant drugs, and anticoagulants were also excluded.

Then the sample was divided into two groups 30 women each. These subjects were randomly divided into control group in odd number and study group in even number. The aim is to evaluate the effects of topical honey dressing on surgical site infection after obstetrical and gynecological abdominal surgery compared to the routine hospital wound care.

A- Control group:They were exposed to the routine wound care of the hospital, which include local antiseptics, daily dressing, cultures from purulent discharge and antibiotic policy.

B- Study group: They were exposed to application honey dressing plus the routine hospital wound care. The amount of applied honey depended on the amount of exudates. Tools of data collection

To achieve the aim of the study the following tools were used.

\section{I- Interview questionnaire was}

developed by the researcher to collect

the required data about the study.

It was comprised of:

1- Sociodemographic data, which include:age, occupation, education, and family history of medical diseases....etc

2- Patient medical history includes:- history of the operation treatment and complications....etc

II: An observation checklist to assess the wound characteristics: site, size, color, odor, amount, type of exudates and pain assessment during hospitalization.

\section{The findings of the current study are as}

\section{follows:-}

There were significant differences in progress of wound healing concerning skin appearance surrounding wound. The differences in progress started to be clear in the $6^{\text {th }}$ day after application of honey 
dressing . The skin became normal in the $9^{\text {th }}$ day in the study group.

Table (1): Represents Follow-up signs of wound assessment (Skin appearance surrounding wound) among the studied subjects (study and control groups).It was observed that, there were statistical significant differences in progress of wound healing concerning skin appearance surrounding wound. In the first three days the skin was White or gray pallor in the two groups, But in the 6th day the difference in progress started to be clear as $(76.7 \%)$ of the study group become pink and $23 \%$ is bright red or blanch to touch. Gradually at the $9^{\text {th }}$ day skin become normal in the study group. Contingency concerning control group there was $(86.7 \%)$ Skin appearance surrounding wound was Bright red or blanches to touch and $(13.3 \%)$ their wound was White or gray pallor or hypo pigmented. Regarding inflammatory response at the $9^{\text {th }}$ day of management, there was not any response in each case in the study group (100\%) But, in the control group there was $(63.3 \%)$ their wound was red and (13.3\%) was red with hotness. But at 21 st day $(86.7 \%)$ of subjects was relived from inflammatory response except (13.3\%) of subjects) were still suffering.

\section{Graph (4) shows illustration of the mean}

rank for the inflammatory variable for

\section{both groups and the results was as}

\section{following:}

- In the first three days, there is difference between the two groups as the control group takes the mean rank value (16.38) and study group takes the mean rank value (44.62) which means that the treatment on the control group has a better effect in that earlier period.

- After six days there is difference between the two groups as the control group takes the mean rank value (17.43) and study group takes the mean rank value (43.57) which means that the treatment on the control group has a better effect.

- After nine days there is difference between the two groups as the control group takes 
the mean rank value (40) and study group takes the mean rank value (21) which means that the treatment on the study group has a better effect at the end of the nine days.

- Exudates disappeared in all subjects $(100 \%)$ in the study group at the $9^{\text {th }}$ day after application of honey dressing, whereas the amount of exudates was large in $(36.3 \%)$ of subjects and small in (36.3\%) of subjects in the control group till the $9^{\text {th }}$ day.

- Concerning control group at $21^{\text {st }}$ day (13.3\%) were purulent and (83.3\%) were changed to serous.

- $\quad$ After the $6^{\text {th }}$ day, all wounds were closed with a remarkably observed improvement in the study group.

- At the $9^{\text {th }}$ day, the pain during wound dressing disappeared in the study group comparing to two third (63.3\%) of subjects were complaining from a severe pain and $(36.7 \%)$ of subjects were complaining from a mild pain in the control group.

- Graph (6) represents distribution of the study groups according to their wound size after 3 weeks of honey application. It was found that the mean of wound length was $15.83 \pm 2.45$ in the study group and $16.37 \pm 2.95$ in the control group. Regarding width of wound after three week of the application of honey, there were significant different. As it was 3-5 $\mathrm{mm}$ in the study group and 5$8 \mathrm{~mm}$ in the control group with mean $4.10 \pm 0.76, \quad$ and $\quad 6.63 \pm 0.96$ respectively.

- After 3 weeks of honey application. Regarding width of wound, it ranged from 3-5 $\mathrm{mm}$ in the study group and from $5-8 \mathrm{~mm}$ in the control group with mean $4.10 \pm 0.76$, and $6.63 \pm 0.96$ respectively 
Table (1): Follow-up signs of surgical site assessment among the studied subjects (study and control groups).

\begin{tabular}{|c|c|c|c|c|c|c|c|c|c|c|c|c|}
\hline \multirow{3}{*}{$\begin{array}{l}\text { Follow-up signs } \\
\text { of surgical site } \\
\text { assessment } \\
\text { ( Skin appearance } \\
\text { surrounding } \\
\text { wound) }\end{array}$} & \multicolumn{6}{|c|}{$\begin{array}{c}\text { Study group } \\
(\mathbf{n}=\mathbf{3 0})\end{array}$} & \multicolumn{6}{|c|}{$\begin{array}{c}\text { Control group } \\
(\mathbf{n}=\mathbf{3 0})\end{array}$} \\
\hline & \multicolumn{2}{|c|}{$3^{\text {rd }}$ days } & \multicolumn{2}{|c|}{$6^{\text {th }}$ day } & \multicolumn{2}{|c|}{$9^{\text {th }}$ day } & \multicolumn{2}{|c|}{$3^{\text {rd days }}$} & \multicolumn{2}{|c|}{$6^{\text {th }}$ day } & \multicolumn{2}{|c|}{$9^{\text {th }}$ day } \\
\hline & $\mathbf{N}$ & $\%$ & $\mathbf{n}$ & $\%$ & $\mathbf{N}$ & $\%$ & $\mathbf{N}$ & $\%$ & $\mathbf{N}$ & $\%$ & $\mathbf{n}$ & $\%$ \\
\hline \multicolumn{13}{|l|}{-Color: } \\
\hline -Pink or normal & 0 & 0 & 23 & 76.7 & 30 & 100 & 0 & 0 & 0 & 0 & 0 & 0 \\
\hline $\begin{array}{l}\text {-Bright red or } \\
\text { blanches to touch }\end{array}$ & 0 & 0 & 7 & 23.3 & 0 & 0 & 0 & 0 & 11 & 37 & 26 & 86.7 \\
\hline $\begin{array}{l}\text {-White or gray } \\
\text { pallor or hypo } \\
\text { pigmented }\end{array}$ & 30 & 100 & 0 & 0 & 0 & 0 & 30 & 100 & 19 & 63 & 4 & 13.3 \\
\hline $\begin{array}{l}\text {-Black or } \\
\text { hyperpigmentate } \\
\text { d }\end{array}$ & 0 & 0 & 0 & 0 & 0 & 0 & 0 & 0 & 0 & 0 & 0 & 0 \\
\hline $\mathrm{X}$ & & & \multicolumn{2}{|c|}{$42.889 *$} & \multicolumn{2}{|c|}{$60 *$} & & & & & & \\
\hline $\begin{array}{l}\text {-Inflammatory } \\
\text { response: }\end{array}$ & & & & & & & & & & & & \\
\hline None & 0 & 0 & 0 & 0 & 30 & 100 & 0 & 0 & 0 & 0 & 11 & 36.7 \\
\hline Redness & 23 & 76.7 & 28 & 93.3 & 0 & 0 & 29 & 96.7 & 28 & 93.3 & 15 & 63.3 \\
\hline $\begin{array}{l}\text { Redness } \quad \& \\
\text { Hotness }\end{array}$ & 7 & 23.3 & 2 & 6.7 & 0 & 0 & 1 & 3.3 & 2 & 6.7 & 4 & 13.3 \\
\hline $\mathrm{X}$ & \multicolumn{2}{|c|}{$56.5^{*}$} & \multicolumn{2}{|c|}{$56^{*}$} & \multicolumn{2}{|c|}{$27.805^{*}$} & & & & & & \\
\hline
\end{tabular}


Graph (4) illustration of the mean rank for the inflammatory variable for both groups

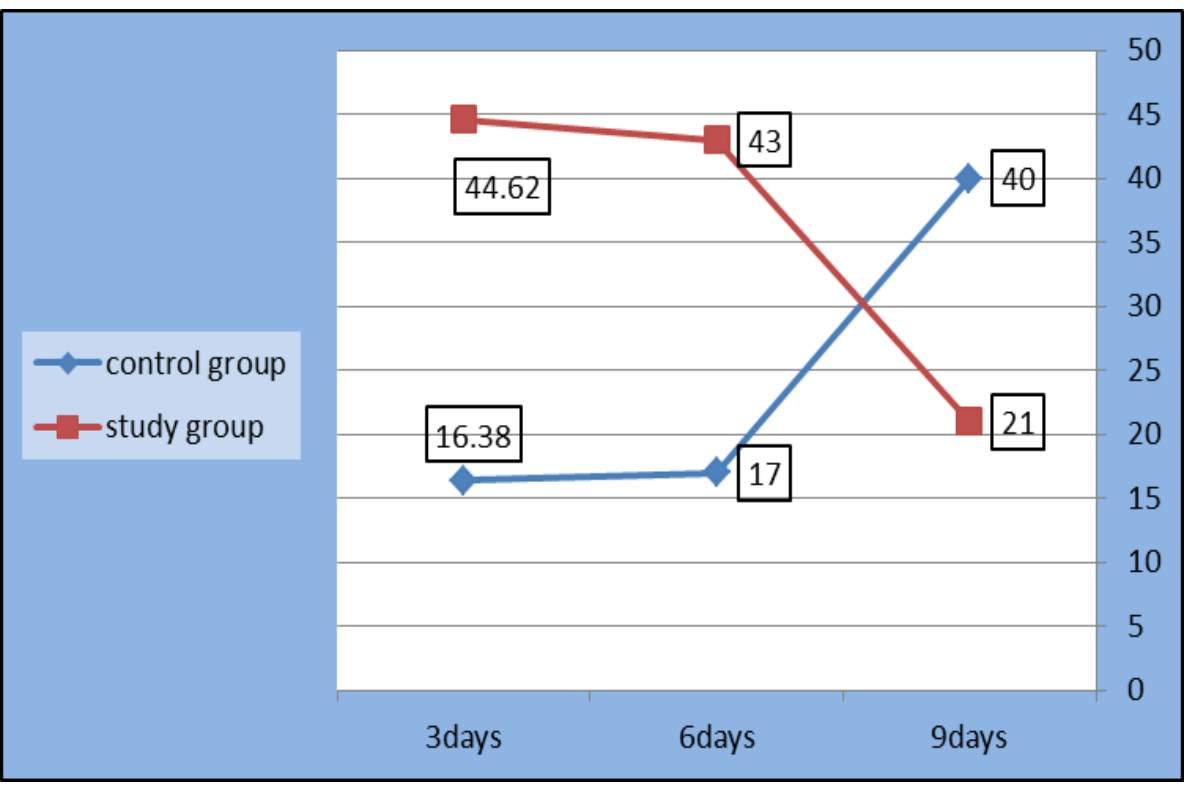

Graph (2): Mean width of wound of the studied groups after 3 weeks of honey application

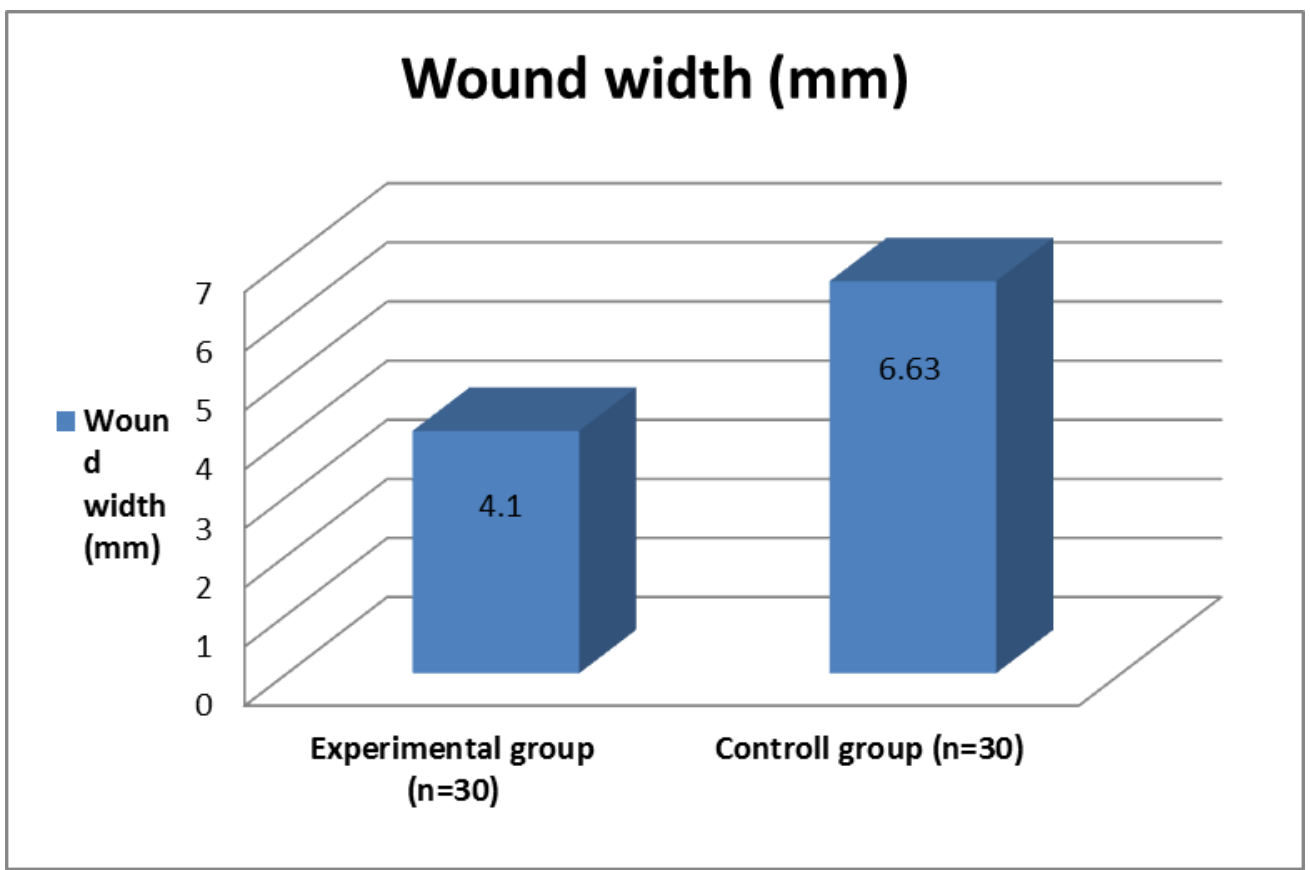

Vol. 3 No. 2 November 2012 


\section{Discussion}

- Socio-demographic data include age, education, occupation, smoking, income, and residency. As determined in the study criteria all women were in childbearing period but the current study revealed that the mean and the standard deviation of the age were 30.87 and 8.41 years respectively for the study group and were 35.17 and 9.92 years respectively for the control group. Most of study group and control group were illiterate. As known from our previous experience, most of the university patients are poor and with low level of education. This was clear in the present study as the majority of subjects were housewives, live in rural area and their income was less than enough. (ElZanaty \& Ann, 2008) ${ }^{(8)}$.

- In the present study, obesity was the most determent grade representing about two fifth in the study group and nearly three fifth in the control group, with considerable percentages of over-weight in both groups. This finding is in accordance with (Nahmias, 2007) ${ }^{(15)}$, who stated that, in 2005 , both the mean and the median of BMI increased to about 28. Obesity and overweight have been increasing in Egypt

over the last decade and are still now at levels that are even higher than those seen in the West. Obese women are more at risk of postpartum complications such as infections, hemorrhage and embolisms. Taken all together, maternal mortality and morbidity is significantly elevated for obese women.

- In the present study concerning the obstetrical history, about half of the two groups were gravid 3-4, Para 3-4. In addition to 3-4 as the number of living children represents the highest percentage in both groups. The majority of subjects were not exposed to abortion. These results approximately match with the study carried out by Nahmias (2007) (16). who had extracted the data from the demographic and health Surveys conducted in Egypt in 1992, 1995, 2000 and 2005. These are large surveys carried out periodically and intended to be uniform to facilitate cross-national comparisons.

- Regarding the types of undergoing surgery, It was observed that, the majority of both groups had under gone cesarean section except about one third had under gone hysterectomy and only (3.3\%) had under gone oophorectomy in 
the control group. Also in the present study, it was observed that the majority of women delivered vaginally in the last delivery followed by current cesarean section. This result is supported by (Khawaja et al, 2009) ${ }^{(17)}$. who reported that, cesarean rates for hospital-based deliveries were much higher than the overall rates, and the rate also increased slightly from a low level of 15.3 percent in the 1992 survey to 18.5 percent in the 1995 survey to 20.9 percent in the 2000 survey, representing a 72 percent increase during the study period. Although the cesarean section rate was slightly higher in private hospitals, the rate also increased consistently in public hospitals. The present study also revealed that, only low pfannenestiel incision was done in all the subjects.

- Concerning recognition of surgical site infections Collier et al (2004) ${ }^{(18)}$, reported that, There are a number of indicators of surgical site infections; include redness, tenderness, infected discharge, a bad smell in the wound, and fever. The patient may have a faster pulse rate and faster breathing, in addition to unexpected pain and/or tenderness either at the time of dressing change or reported by the patient even when the wound dressing is in place. After careful assessment, it is apparent that the wound is infected, it is important to confirm this and identify the causative $\operatorname{organism}(\mathrm{s})$ and possible sensitivities to antibiotics.

- In the present study, the first indicator of surgical site infections was the increase of body temperature to $38{ }^{\circ} \mathrm{C}$ or more for 24 hours for all cases. Then positive wound culture for all cases. The third indicator was the local signs, it was detected that more than half of wounds in the study group were erythematized compared to entire control group. Although pain was present in all cases of the two groups, it was different in severity and quality. While pain was moderate in the entire study group, it was mild in about one quarter and moderate in about three quarters of the subject of the control group. Pain was intermittent all over the time. All studied groups were felt stabbing pain compared to the control group, half of them were felt stabbing pain and the other half were felt aching pain. 
- In addition, the researcher confirmed diagnosis of surgical site infections among the studied subjects (study and control groups) by wound culture. Regarding wound culture, it was found that, the causativeorganisms, Gram -ve organisms represent two fifth in the study group and more than three fifth in the control group while Gram +ve organisms represent the majority in the study group and more than a half in the control group. On the other hand, Staff org. represents more than three fifth and about one quarter, Pseudomonas represents one fifth and nearly two fifth and Proteus represent represents about half and one fifth in the study and control group respectively.

- Regarding sensitivity to antibiotic, in the study group, about one quarter of the subject was sensitive to Amoxicillin and one quarter was sensitive to cefotax compared to one tenth of subjects in the control group. In addition to more than two fifth of subjects in the study group were sensitive to another type of antibiotics as ciprofloxacin \& levofloxacin compared to four fifth of subjects in the control group. This finding is in accordance with Al-Waili's and Saloom's (1999) ${ }^{(3)}$ who reported that, Period for antibiotics use was 6.88 $+/-1.7$ days in the study group and 15.45 $+/-4.37$ in the control group ( $\mathrm{p}<0.05)$. They also stated that complete wound healing was evident after $10.73+/-2.5$ days in the study group and after 22.04 $+/-7.33$ in the control group.

- Concerning results of wounds culture, 7 days after honey application, the majority of study group were negative and less than two fifth were positive. on the other hand all the control group (100\%) were positive. This finding is in accordance to Al-Waili's and Saloom's (1999) ${ }^{(3)}$ who reported that, eradication of bacterial infections was obtained after $6+/-1.9$ days (mean +/- SD) in the study group using topical honey, and after $14.8+/$ 4.2 days in the control group who didn't not use topical honey.

- This finding is ascribed to that; honey provides a moist healing environment and prevents bacterial growth even when wounds are heavily infected. Honey is a very effective mean of quickly rendering heavily infected wounds sterile, without the sideeffects of antibiotics, and it is effective against antibiotic-resistant strains of bacteria. 
Its antibacterial properties and its viscosity also provide a barrier to cross-infection of wounds. (Molan, 2001 ${ }^{(10)}$.

- Moreover, concerning wound size in the present study, the wound lengths didn't exceed $20 \mathrm{~cm}$ in both groups with mean $15.83 \pm 2.45$ in the study group and $16.37 \pm 2.95$ in control group. Regarding width of wound after three week of the application of honey, it ranged from 3-5 $\mathrm{mm}$ in the study group and from 5-8 $\mathrm{mm}$ in the control group with mean $4.10 \pm 0.76$, and $6.63 \pm 0.96$ respectively. This finding is in accordance to AlWaili's and Saloom's (1999) ${ }^{(3)}$ who reported that, Size of postoperative scar was $3.62+/-1.4 \mathrm{~mm}$ in the study group which used topical honey and was 8.62 +/- $3.8 \mathrm{~mm}$ in the control group who did not use topical honey.

- In the current study the researcher used a follow up record to assess prognosis of infected surgical site. the researcher categories the time variable to three, six and nine days, the main objective is to do a comparison between study group ( women exposed to honey dressing + routine hospital wound care hospital wound care) and control group (women exposed to routine hospital wound care hospital wound care only) and the results was as following:

- Concerning skin appearance surround wound. In the first three days the skin was White or gray pallor in the two groups, But in the 6th day the difference in progress started to be clear as more than three quarter of the study group become pink and one quarter is bright red or blanch to touch. Gradually at the $9^{\text {th }}$ day skin become normal in the study group. Contingency concerning control group the majority of Skin appearance surrounding their wound was Bright red or blanches to touch and less than one fifth their wound was White or gray pallor or hypo pigmented. In addition; regarding inflammatory response at the $9^{\text {th }}$ day of management, the inflammatory response disappeared in the entire study group. But, most of the control group their wound was red and less than one fifth was red with hotness.

- Regarding exudates amount there were significance difference between study group and control group, the in the exudates disappeared from the majority of the study group at the 6th of management. On the other hand, the 
exudates amounts were moderate in all the control group. In the $9^{\text {th, }}$ the exudates disappeared completely from the study but still large in the most of the control group. At the $21^{\text {st }}$ of wounds managements the amounts of exudates in the majority of the control group were very scant except more than one tenth were large until the $21^{\text {st }}$ of wound managements.

- When exploring the type of exudates especially at the 9th day of management the exudates were absent completely in the study group. During exploring the control group it was observed that one third of them were foul purulent ,about one fifth were purulent, about one fifth were serous, one fifth were was Serosanguieous and one tenth was bloody. In the day $21^{\text {st }}$ still more than thirteen percentages were purulent and the majorities were changed to serous.

- This may be due to Honey provides a supply of glucose for leucocytes, which is essential for the respiratory burst that produces hydrogen peroxide, which is the dominant component of the antibacterial activity of macrophages. Furthermore the use of honey provides substrates for glycolysis, which is the major mechanism for energy production in the macrophages, and thus allows them to function in damaged tissues and exudates where the oxygen supply is often poor. In addition, the acidity of honey (typically below $\mathrm{pH}$ 4) may also assist in the antibacterial action of macrophages, as an acid $\mathrm{pH}$ inside the vacuole is involved in killing ingested bacteria. Whether it is through this action, or through preventing the toxic unionized form of ammonia from existing that is involved, topical acidification of wounds promotes healing. The high glucose levels that the honey provides would be used by the infecting bacteria in preference to amino acids from the serum and dead cells, and thus would give rise to lactic acid instead of ammonia and the amines and sulphur compounds that are the cause of malodour in wounds. (Leveen et al, 1973) ${ }^{(20)}$.

- Regarding the wound status, it was observed that, there were improvements in the study group throughout six days of honey application. On the other hand, the deterioration started to appear in the 
control group, but at the $9^{\text {th }}$ day, more than two thirds of control group showed a slight improvement. Also at the $21^{\text {st }}$ day, the majority of subjects in the control group showed a significant improvement, and less than one fifth of them their wounds were deteriorated.

- This finding is in accordance to AlWaili's , Saloom (2005) ${ }^{(3)}$. who reported that, after using honey, (84.4\%) of patients showed complete wound healing without wound disruption or a need for re-suturing and only (4) patients showed mild dehiscence. In their control group, (50\%) of patients showed complete wound healing and $(50 \%)$ of patients showed wound dehiscence, half of them needed re-suturing under general anesthesia $\left(\right.$ Molan, 2005) ${ }^{(\mathbf{1 0})}$.also reported that honey used as a wound dressing has been promoted the formation of a clean healthy granulation tissue, promoted epithelialisation of the wound, Improvement of nutrition of wounds has been observed, increased blood flow has been noted in wounds, and free flow of lymph. Another effect of honey on wounds has been noted is, it reduces inflammation and hastens subsidence of passive hyperemia. It also reduces edema and exudation, and absorbing fluid from the wound. This may be due to that, honey is be expected to have a direct nutrient effect on regenerating tissue because it contains a wide range of amino acids, vitamins and trace elements, in addition to large quantities of readily assimilable sugars. The vitamin $\mathrm{C}$ content of honey, which is typically more than three times higher than that in serum, and may be many times higher, it could be a particular importance because of the essential role of this vitamin in collagen synthesis. In addition, the high osmolarity of honey causes an outflow of lymph which serves to provide nutrition for regenerating tissue which otherwise can only grow around points of angiogenesis (seen as granulation). Healing is delayed if the circulation to an area is poor, or if a patient is poorly nourished. Also it has been suggested that, the decreased turgor resulting from the application of honey may increase oxygenation of tissues. In addition, honey gives a fast rate of tissue regeneration and suppression of inflammation, oedema, exudation and malodour in wounds. The antibacterial properties clearing infection could alone account for these effects by preventing the production of the products of bacterial 
metabolism which are responsible for the contrary conditions. Furthermore, honey has a direct trophic and anti-inflammatory effect on wound tissues (Efem, 1988) ${ }^{(\mathbf{2 1})}$.

- Regarding pain during wound dressing in the beginning there were no difference, but at the $9^{\text {th }}$ day the pain disappeared in the study group but in the control group, there were two third of subjects complaining from severe pain except around two fifth of subjects whose pain was slight. At the $21^{\text {st }}$ day, concerning the control group, thirteen percent of subjects were having a severe pain and the rest were having a slight pain. This result is in accordance with Molan's (2005) ${ }^{(\mathbf{1 0})}$ who reported that, honey is soothing when applied to wounds and that honey causes no pain on dressing or causes only momentary stinging. They also added that honey is non-irritating, causes no allergic reaction, and has no harmful effects on tissues. In addition, it has been noted that, honey dressings are easy to apply and to remove because there is no adhesion to cause damage to the granulating surface of wounds. Honey also causes no bleeding when removing dressings. Any residual honey is easily removed by simple bathing.
- Concerning duration of wound management, the study group did not exceed 11 days in wound management but the control group exceeded 21 days. All women in the two groups were taken antibiotics and analgesics according hospital routine. This result matches with Efems' et al (1988) ${ }^{(21)}$ who reported that, the wounds become sterile in 3 - 6 days, or 7 - 10 days after clinical studies on the usage of honey as a dressing for infected wounds and with Molan's who reported that, the mean hospital stay was $9.36+/-1.8$ days in group A (treated by honey dressing) and 19. $91+/-7.35$ days in group B (treated according hospital routine).

- There is also an economical advantage of using honey as a wound dressing. This is seen in the direct cost savings when compared with conventional treatments and in the savings in ongoing costs when consideration is given to the more rapid healing rates that are achieved. Other observations on cost savings have been use of antibiotics ceased, length of hospitalization reduced by at least half.

- To conclude that, various studies on the usage of honey as a dressing for infected wounds have reported that, the wound become sterile in 3-10 days. Honey used as wound dressing has been reported to promote the formulation of clean healthy 
granulation tissue. It has also been reported to promote epithelialisation of the wound and rapid growth of new tissue is remarkable. Inflammation, swelling and pain are quickly reduced, odor is reduced, sloughing of necrotic tissue is induced, and healing occurs rapidly with minimal scarring. Improvement of wounds nutrition has been noted in addition to free flow of lymph. Finally, topical honey dressing as alternative method of managing abdominal surgical site infections provides a specific desirable affects (Ahmed, 2003) ${ }^{(23)}$.

\section{Conclusion}

Based on the findings of the present study, the researcher can conclude that topical application of sterile honey could eradicate organisms within a short period of time, reduce the period of antibiotic use, accelerate the healing process in a unique and an economic way, result in minimal scar formation, prevent wound dehiscence and the need for re-suturing

\section{Recommendation:}

-Mass media should be utilized for the dissemination of simple, correct and relevant information about honey dressing for infected wound.

-The use of standardized scale for measuring surgical wound healing must be an integral part of surgical wound managements

-Herbal management of surgical site infections should be included in the curricula of basic nursing education and continuing education in variable nursing educational settings.

-Appropriate and accessible public services which include information, education and counseling about herbal management of surgical site infections must be included in the health care delivery system.

Recommendations (Suggestion) for further studies:-

Studies to find out factors that affect the dissemination and implementation of up to date information about complementary therapy for surgical site infections.

- Replication of the present study at different settings and among different samples of selected high risk women for surgical site infections.

- Studies about the effect and techniques of complementary therapy on surgical site infections.

- The study need to be conducted on a larger sample and be extended for a longer period of time to allow 
generalization of the results. 6- The study can be conducted on any age of women, any post operative abdominal obstetrical or gynecological patients, women with medical disorder as cardiac failure, chronic respiratory problems, vascular disorders, diabetes, renal and liver insufficiency, patients with hemoglobin $\leq 8 \mathrm{mg} / \mathrm{ml}$, and patient receiving drug therapies which interfere with wound healing as chronic steroid therapy, imunosuppressant drugs, and anticoagulants.

\section{References}

1-Gibbons L., Belizán J. M., Lauer J. A., Betrán A. P., Merialdi M. \& Althabe F. World Health Report Background Paper: The Global Numbers and Costs of Additionally Needed and Unnecessary Caesarean Sections Performed per Year: Overuse as a Barrier to Universal Coverage, (2010). Available at http://www.who.int/healthsystems/topics/ financing/healthreport/30C-

sectioncosts.pdf. Last accessed on 10th Feb 2012.

2- Shetty Jyothi, Vyas Neetha M, Kumar Pratap, Kamath Asha. Antibiotic prophylaxis for hysterectomy and cesarean section:Amoxicillin-clavulanic acid versus cefazolin:J Obstet Gynecol India Vol. 60, No. 5 : September / October, 2010; 419 - 423.

3-Al waili, N., S., Saloom, K., Y. Effects of topical honey on post-operative wound infections due to gram positive and gram negative bacteria following caesarean sections and hysterectomies. European journal of medical research, 1999 ; 4 (3): 126-130.

4- Salah, R. Ahmed, Mostafa A. A. Ellah, Osman A. Mohamed, and Hesham M. Eid, Prepregnancy Obesity and Pregnancy Outcome, Department of Obstetrics \& Gynecology, Sohag University Hospital, Egypt, International Journal of Health Sciences, 2009; Jul; 3(2)203-208.

http://www.ncbi.nlm.nih.gov/pmc/article s/PMC3068823/

sited at 15 jul 2012

5-World Health Organization (WHO). WHO Guidelines on Hand Hygiene in Health Care. Geneva, Switzerland: 2009; WHO Press. Available at: http://whqlibdoc.who.int/publications/20 09/9789241597906_eng.pdf. Accessed October 12, 2010. 
6- Jyothi S., Neetha V., Pratap K., Asha K. Antibiotic prophylaxis for hysterectomy and cesarean section: Amoxicillinclavulanic acid versus cefazolin. J Obstet Gynecol India, 2010; (60) 419 - 423.

7- Ministry of Health and Population Egypt (MOHP). Standards of practice for integrated maternal and child health and reproductive health services, First edition, Infection Control Department, 2005;MOHP Egypt. Available at http://pdf.usaid.gov/pdf_docs/PNADF09 2.pdf. Last accessed on 25th January 2012.

8- El-Zanaty, F. \& Ann, W. Egypt Demographic and Health Survey. Kasr Al-Aini Journal Of Obstetrics \& Gynecology, 2008; Egypt Ministry of Health. Available at http://www.measuredhs.com/pubs/pdf/F R220/FR220.pdf. Last accessed on 26th January 2012.

9- Spry, C. Essentials of perioperative nursing. Jones \& Bartlett Learning, 2009, 214

10- MOLAN, P .Mode of action, In White, R; Molan, P; Copper, R (eds) Honey: A modern wound management product,

Wounds UK; Aberdeen, 2005; 1-23.
11- Banister, E., Schreiber, R. The tyranny of consensus: Implications for nursing education. International Journal of Nursing Education Scholarship, 2004; 1(1). Retrieved from http://www.bepress.com/ijnesnaty. Last accessed on 22/10/2011.

12- Pillitteri, A. Maternal \& child health nursing care of the childbearing and childrearing family, $4^{\text {th }}$ ed., USA, Lippincott Williams\& Wilkins, 2003; 540-49,552-57,596-98,604-6.

13- Nettina, S. Lippincott manual of nursing practice. (9th ed. ed.). Ambler, PA: wolters kluwer/lippincott Williams, 2010;.212.

14- World Health Organization (WHO). Traditional medicine,(2008; Fact sheet $\mathrm{N}^{\circ} 134$

15- World Health Organization (WHO). Prevention of hospital-acquired infections A practical guide, 2nd edition. 2002; Available at http://www.who.int/csr/resources/publica tions/whocdscsreph200212.pdf

16- Nahmias, P. Trends in the prevalence of overweight among women in Egypt. Vol. 33, Iss. 3, 01 oct. , 2007; 108 - 110 
17- Khawaja, M., Choueiry, N., Jurdi R. Hospital- based caesarean section in the Arab region: An overview. Eastern Mediterranean health Journal, 2009; 15(2). 459.

18- Collier M., Recognition and management of wound infections, Published: Jan 2004.

http://www.worldwidewounds.com/2004 /january/Collier/Management-of-Woundinfections.html Last Modified: Monday, 18-Oct-2004 14:11:49 BST

19- Culligan, P., J., Kubik, K., Murphy, M., Blackwell, L., Snyder, J. A randomized trial that compared povidone iodine and chlorhexidine as antiseptics for vaginal hysterectomy. Am J Obstet Gynecol, 2005; 192(2): 422-425.

20-Leveen, H.,H., $\quad$ Falk, G., $\quad$ Borek, B., et al. Chemical acidification of wounds: an adjuvant to healing and the unfavorable action of alkalinity and ammonia. Ann Surg., 1973;178(6): 745753

21- E FEMS'. E. Clinical observations on the wound healing properties of honey 183. British Journal of Surgery, 1988; 75: 679-681.
22- Centers for Disease Control and Prevention (CDC). (2012). Frequently Asked Questions about Surgical Site Infections. Available at http://www. cdc.gov/HAI/ssi/faq_ssi.htm l\#a1. Last accessed on 25th January 2012.

23-AhmedA, HoekstraM, Honey medicated dressing transformation of an ancient remedy transformation of an ancient remedy intomodern therapy.Annals of plastic surgery , 2003;50(2):143-147 